\title{
La estética del juego político en el marco de la Femocracia Sur Americana durante el primer gobierno de Dilma Rousseff (2011-2014)*
}

\author{
The aesthetics of the political game within the framework \\ of the South American Femocracy during the first \\ government of Dilma Rousseff (2011-2014)
}

\author{
FERnanda Pattaro Amaral \\ Ana CláUdia Delfini CaPistrano de Oliveira** \\ Docente-investigadora del Mestrado em Gestão de \\ Políticas Públicas - UNIVALI, SC. Brasil \\ Coordinadoras de estudios multidisciplinares de género \\ de la Red-HILA (Red Iberoamericana de Ciencias \\ Sociales con enfoque de género) - SP/Brasil
}

Recibido: 10/5/2016

Aceptado: $14 / 11 / 2016$

doi: https://doi.org/10.20318/femeris.2017.3551

Resumen. Este artículo intenta hacer una reflexión primaria sobre la Femocracia en el gobierno de Brasil en la figura de la jefa de Estado: Dilma Rousseff en su primero mandato (2011-2014). El concepto de Femocracia es un concepto bastante contemporáneo y poco analizado, sobre todo en los recientes gobiernos dirigidos por mujeres. Además, también es posible a la luz del concepto de Femocracia sacar algunos prejuicios dirigidos a las mujeres por el hecho de ser mujeres y su pertenencia al terreno del poder - predominantemente masculino, sobretodo en Suramérica. La metodología utilizada ha sido una revisión de la literatura pertinente sobre el pensamiento político, el feminismo en Brasil y el cruce de esas dos vertientes, y los analices del gobierno mencionado a la interpretación de la Femocracia. Los resultados son importantes en el sentido de que el término es relativamente nuevo y existe, por lo tanto, un gap político sobre los gobiernos ejercidos por las mujeres interpretados a la luz posmoderna de la Femocracia; además, el hecho de la existencia de tecnócratas feministas en los gobiernos demanda la aplicación de términos propios para realiza los análisis pertinentes a una nueva realidad destacada por la lucha de las mujeres por el espacio público.

Palabras clave: femocracia, democracia, género, Brasil, Dilma Rousseff.

Abstract. This article aims to make a primary reflection about Femocracy in Brazilian government by its Head of State: Dilma Rousseff in her first government (2011-2014). The concept of Femocracy is a fairly contemporary concept and little discussed, especially in recent governments led by women. In addition, it is also possible in the light of the concept of Femocracy take some prejudices aimed at women because they are women and they are working

\footnotetext{
*Agradecemos al amigo Edgar Lara López por la revisión del texto y las contribuciones intelectuales.

**fpa.sociologia@gmail.com / anaclaudia.univali@gmail.com
} 
in the field of politics - predominantly male, especially in South America. We will work in this article the concept of aesthetic politics in a femocratic government to trim the issue and gain some depth theoretical discussion and practical application on a government. The methodology used will be a review of the relevant literature on political thought, feminism in Brazil intertwining these two aspects, and analyze the government referred by the Femocracy concept. The results are important in the sense that the term is relatively new and there is, therefore, a political gap on governments exercised by women interpreted in the postmodern concept of Femocracy, also we have the fact of the existence of feminist technocrats governments that demand the applicability of own terms to analyze relevant actions brought by the new reality by leading the struggle of women for public space.

Keywords: femocracy, democracy, gender, Brazil, Dilma Rousseff.

\section{Introducción. La política para los hombres}

El filósofo Platón (2004) sostenía que la política era el espacio donde se podría construir un mundo aparte, donde todo sería perfecto bajo los ojos de su creador, para reemplazar el actual mundo en creciente deterioro. Así, podemos afirmar que ese mundo construido por la política está hecho a la imagen de sus creadores - los que detienen la legitimidad del ejercicio del poder político. Velozmente la política se asoció a un mecanismo poderoso de dominación, que históricamente está asociado a la supresión de libertades (físicas, concretas o simbólicas, sicológicas) de un grupo sobre otro. Ese poder se ve aplicado institucionalmente cuando el Estado tiene la legitimidad del uso de la fuerza, la cual puede conducir a que la dominación sea percibida como algo natural, incluso los excesos de la utilización del poder; esto puede derivar a lo que Foucault (1995) llamó "formas patológicas - enfermedades del poder", en donde el uso excesivo del poder posibilitó el desarrollo de modelos políticos totalitarios como el fascismo y el estalinismo.

Para comprender las relaciones de poder hay que observar no solamente el poder ensimismo o sus racionalidades, sino también las formas de resistencia y el ejercicio de lucha en contra las relaciones de poder, ya que esencialmente que se juega son las resistencias que se ponen hacía las formas de poder que sujetan los individuos, sea mediante control y dependencia, o mediante su propia identidad (Foucault, 1995).

La idea de la dominación siempre fue una idea "masculina", ha sido (y sigue siendo) asociada a atributos considerados masculinos, como la fuerza, la virilidad, el heroísmo y la robustez, lo que hace de la propia política un campo enmarcado por discursos y practicas sexistas. Los movimientos feministas, en sus diversos segmentos, siempre han cuestionado las relaciones de poder que resultan en dominación, explotación y sujeción de las mujeres y sus cuerpos, en cualquier área (sea religiosa, sea sexual, sea política o económica). El feminismo de la primera ola (siglo XVIII y XIX) fue marcado, sobre todo, por las luchas hacía la dominación y explotación política en nombre de la garantía de los derechos civiles y el sufragio, al paso que en la segunda y tercer ola (siglo XX) se han evidenciado la lucha identitaria hacia las formas de sujeción femenino que se tradujo en las demandas por la igualdad, la libertad, la sexualidad y la democracia femenina ${ }^{1}$.

\footnotetext{
${ }^{1}$ En este sentido, iremos explorando el concepto de la femocracia en el contexto de las luchas feministas dentro del campo político, exponer algunos prejuicios dirigidos a las mujeres por el hecho de ser mujeres y su pertenencia al ter-
} 


\section{La Democracia y la República: la política a los ciudadanos}

La Democracia Griega se sitúa cerca de los siglos VIII a.C - IV a.C., en la cual el poder político emanaba del centro hacia los alrededores, requiriendo la presencia y participación de los ciudadanos, que, por su vez, constituían un 10\% de la población griega representadas por hombres, pues la democracia estaba negada a las mujeres, los/as niños/as, los esclavos y extranjeros. Por lo tanto, la democracia ${ }^{2}$ en su nacimiento ya era un régimen de exclusión.

Platón (2004) a su vez, afirma que la República era algo sofisticado y que su conducción debería estar a cargo de una elite intelectual, pues "la pólis es un organismo moral" cuya finalidad es "la realización de la justicia y de la virtud" (Oliveira, 2014, p.33), y para eso existe la necesidad de profundo conocimiento de sus estructuras. La democracia como tal permite que los actores no aptos al ejercicio de la política lo ejerciesen y eso podría instaurar un gobierno de "ineptos que ponen en riesgo el orden moral e institucional de la pólis" (Oliveira, 2014, p.34).

Aristóteles (2004) también hizo análisis sobre la política y la democracia, el cual diserta sobre el gobierno democrático en el rol del Estado en su estudio intitulado "Política"3. Aun siendo cuestionado sobre el poder familiar, Aristóteles (2004) afirma que el dominio natural del hombre sobre la mujer es del tipo político, más estadista, mientras que sobre los hijos es más real, como lo de un rey. Además de considerar la mujer inferior al hombre por su naturaleza, se puede decir que su concepción de la democracia como un modelo de gobernabilidad del pueblo y para el pueblo no es totalmente acertada, puesto que estaban excluidos de la vida y vivencia políticas las mujeres, los esclavos, los/as extranjeros/as y los/as niños/as.

\section{John Locke y el patriarcado}

Siempre manteniendo el focus en la comprensión del contexto histórico de cada acontecimiento humano/social, empezaremos esta parte trabajando las perspectivas de algunos pensadores del siglo XVIII sobre el comportamiento social de la mujer de esa época que enmarca una división en términos de ruptura entre la Ciencia y la Religión (Siglo de las Luces - Ilustración). John Locke es la base fundamental para la comprensión de la teoría política moderna y las democracias liberales.

reno del poder - predominantemente masculino, sobretodo en Suramérica. La metodología utilizada será una revisión de la literatura pertinente y los analices del gobierno mencionado a la interpretación de la Femocracia. Los resultados son importantes en el sentido de que el término es relativamente nuevo y existe, por lo tanto, un vacío político sobre los gobiernos ejercidos por las mujeres interpretados a la luz posmoderna de la Femocracia.

${ }^{2}$ Algunos teóricos como Carole Pateman (1992) y Norberto Bobbio (2000) apuntan las dudas y dificultades de colocar en práctica un gobierno del pueblo y para el pueblo (el principio máximo de la democracia). Bobbio justifica que la burocracia y la lentitud del proceso dificultan la concretización de un proyecto político democrático. Es oportuno mencionar que la no incorporación de la mujer como actriz política es otro obstáculo para la concretización de esa democracia.

${ }^{3}$ En el tomo I, capítulo I, párrafo 10. 
Las tesis políticas de John Locke tuvieran importancia vital para el desarrollo de la democracia liberal de occidente, así como fundamento de las revoluciones inglesa y francesa, e incluso fueron la base de la teoría de la separación de los poderes, de Montesquieu, y la Declaración de Independencia de los Estados Unidos.

Desde el momento de su definición sobre el poder político, Locke afirma que el hombre políticamente debe gobernar su mujer, ya que ésta es políticamente incapaz de autogobernarse, es decir que dada a su naturaleza la mujer es incapaz o no fue dotada de capacidades para ejecutar algún, de tal manera que se concibe un cómo ser necesitado de un ente más poderoso o capaz para gobernarla en sociedad ${ }^{4}$. No obstante, el autor ha contribuido al logro de algunos avances femeninos en el terreno de los derechos igualitarios (Rodrigues, 2004; Hirschmann \& Mcclure, 2007; Sommerville, s.f).

En el calor de los intensos debates políticos, las tesis sobre el derecho natural de las mujeres ganaban impulso con las obras de John Locke. En 1690, cuando el escribe su obra principal, "Dos Tratados sobre el Gobierno", se trabaja los principales puntos estructurales de las democracias liberales. ${ }^{5}$ Sobre la sociedad política o civil, Locke (2003) expone esa idea contractual entre el hombre y la mujer en la sociedad conyugal:

Pero marido y mujer, aunque compartiendo el mismo cuidado, tienen cada cual su entendimiento, por lo cual inevitablemente diferirán en las voluntades. Por ello es necesario que la determinación final (esto es, la ley) sea en alguna parte situada: y así naturalmente ha de incumbir al hombre como al más capaz y más fuerte. Pero eso, que cubre lo concerniente a su interés y propiedad común, deja a la mujer en la plena y auténtica posesión de lo que por contrato sea de su particular derecho, y, cuando menos, no permite al marido más poder sobre ella que el que ella gozare sobre la vida de él (Locke, 2003, p.79).

Algunas interpretaciones feministas sobre las principales tesis políticas de John Locke fueron trabajadas especialmente sobre sus ideas en cuanto a la propiedad y la refutación al patriarcado de Robert Filmer (1680), pero esta última se mantuvo solo sobre el hecho de que el poder no emanaría naturalmente del Estado, mientras que el padre (de familia) tendría poder sobre su familia (hijos/as y mujer, claro). Así nos presenta la situación Johann Sommerville (s.f) ${ }^{6}$ :

\footnotetext{
${ }^{4}$ Paréceme oportuno, para este propósito, definir lo que entiendo por poder político; que el poder de un magistrado sobre un súbdito es distinto del poder del padre sobre los hijos, del señor sobre sus sirvientes, del marido sobre la mujer, y del noble sobre el esclavo. Como esos diversos poderes están a veces reunidos en la misma persona, si la observamos desde esos diferentes puntos de vista, podría ser de utilidad distinguir tales poderes unos de los otros, apuntando las diferencias entre un jefe de comunidad, un padre de familia y un comandante (Locke, 2003, p.22).

${ }^{5}$ El primer tratado refuta la obra "El Patriarcha", de Robert Filmer (1680), que trabaja con la línea central del poder naturalmente emanado por el padre sobre sus hijos (y no porque los hijos aceptaron y le concedieron ese poder) y, consecuentemente, del padre (gobierno) sobre los hijos del Estado (pueblo/ciudadanos). De esa forma, Filmer (1680) puso en la misma ecuación los dos poderes emanados por los dos "padres", mientras Locke afirmaba que se trataba de dos poderes diferentes, pues el poder del padre sobre la familia era diferente del poder político (Sommerville, s.f.). El Segundo Tratado (2003) refuta esa idea de Filmer, sosteniendo que los seres son libres por naturaleza y que pactan entre sí en un contrato social. Su tesis es basada en el individualismo.

${ }^{6}$ El autor explicita la forma como Locke intentó anular la tesis sobre el poder patriarcal de Filmer, pero en realidad, puede que el mismo Locke utilizó el concepto validando el poder natural del padre sobre la familia, solamente haciendo la distinción cuando se trataba del poder político emanado del Estado.
} 
Según Locke, las personas nacen libres e iguales; pero considero a bien que los hombres gobernaran el Estado así como la familia; y no sugirió nada con respecto a la participación de las mujeres en el poder político. Filmer mismo señaló que los principios democráticos genuinos (que él rechazó) involucraban el empoderamiento de las mujeres (y, añadió, de los niños también; él también afirmó que un verdadero demócrata querría ganar un nuevo voto a cada vez que alguien nace o muere). Si se argumenta que las mujeres y los niños son subordinados a los hombres, Filmer sugirió, que se admite que Adán era superior a todos los demás que vivieron mientras él vivió; pero si es así, no puede haber ningún motivo para suponer que en un primer momento el poder estaba en manos del pueblo en su conjunto, y que fue trasladado solamente más tarde a los reyes (Sommerville ${ }^{7}$, s.f).

Rodrigues (2004) todavía tiene una opinión un poco diferente sobre el mismo tema. Para la autora, Locke al defender los derechos individuales manifestó un liberalismo que aportó más inclusiones que exclusiones a las mujeres en la sociedad ${ }^{8}$. Todavía, la autora está de acuerdo con la crítica feminista de que ese poder patriarcal cedido a los hombres marcó la posición social y política de las mujeres en un momento de vital importancia para el desarrollo de un modelo democrático - el liberal. La autora afirma que las interpretaciones feministas acusan a Locke de estar de acuerdo con un poder natural de los hombres sobre las mujeres (el poder marital), y así de la subordinación natural de la mujer al hombre. Eso compromete la prometida igualdad social promulgada por Locke, porque las mujeres al estar sumisas a un poder patriarcal (para citarnos a Filmer) están excluidas de todas las decisiones políticas. Sin embargo Rodrigues (2004) defiende al autor afirmando que Locke fue rehén de las condiciones históricas de su época, y desde su punto de vista defiende lo que acredita ser la verdad natural; que no habría intención de hacer una distinción entre las capacidades intelectuales de mujeres y hombres.

Hirschmann and McClure (2007), a su vez, reafirman que Locke fue bastante progresista al idealizar los derechos igualitarios de las mujeres a lo de los hombres, y al advertir la división de la tarea de los cuidados con los/as niños/as, que el contrato matrimonial era una opción de ambos y que el divorcio era igualmente una opción válida para cualquier uno de la pareja. Hirschmann and McClure (2007) afirman que Locke también era partidario de una educación para niños y niñas, o sea, que ambos sexos tuvieron tutores para su educación, no solamente los niños. ${ }^{9}$

La autora Terrell Carver (2007), analizó el género y las narrativas en la obra "Dos Tratados" de John Locke a través de los "lentes del género" (Carver, 2007, p.187) y de los

\footnotetext{
${ }^{7}$ Sin paginación.

${ }^{8}$ Él "abrió nuevos lugares para las mujeres al garantizarles los derechos a la propiedad, sean ellas casadas o no, así como fomentó la división de la responsabilidad dentro de la familia con el cuidado con los/as niños/as divididos entre el esposo y el padre" (Rodrigues, 2004).

${ }^{9}$ Melissa Butler (2007) afirma que los ataques liberales a la teoría del patriarcado (con liberales como John Locke) en el siglo XVII buscaban una ruptura con el modelo dominante en Inglaterra cuyo mayor exponente era Sir Filmer (1680), que preconizaba que "nadie nace libre; todos nacieron en sujeción a algún ente patriarcal superior". Con eso, Locke cambión el entendimiento de la mujer dentro de la familia, y que pese a que la sumisión de la mujer al hombre se mantuvo en sus textos, él hizo creer que ese poder no era natural, no era divino, sino que consentido por las partes - o una de las partes. De todas formas, las mujeres no logran más derechos civiles garantizados en Locke que en Hobbes o en Filmer (Hirschmann \& McClure, 2007).
} 
estudios históricos de hombres y masculinidades, la autora revisó algunos conceptos de Locke a la luz de los estudios de género de finales del siglo XX e inicio del XXI. La autora trabaja sobre la identificación del concepto genérico de hombre, argumentando que la crítica feminista lo percibe como "un cuerpo incapaz de gestar, y como una persona competitiva y con interés propio" (Carver, 2007, p.188). De esa forma, sigue la autora, las feministas también critican ese cuerpo por ser al mismo tiempo sexuado y asexuado, según los ambientes público/privado. Así, el sexo y la reproducción están relegados al ambiente privado -y por consecuencia las mujeres también (porque son las máquinas reproductoras de la sociedad). En tanto que el poder público pertenece a los hombres asexuados- los hombres públicos ${ }^{10}$. En las narrativas del Segundo Tratado, está la asociación de las mujeres con la reproducción y la maternidad, así como la asunción de que el rol de las mujeres pertenece a un ambiente privado o doméstico, pero no público, o sea "pre-political" (Carver, 2007, p.189), lo que incita al pensamiento de que el hombre público aparenta ser una persona sin sexo. Shanley (2007), al analizar el contrato matrimonial y social en el pensamiento político del siglo XVII afirma que Locke - en ese punto - ha sido bien importante cuanto al derecho igualitario entre los géneros porque ha asumido que el matrimonio era una relación "contractual", o sea, pactada entre las dos partes, negociable en cuanto a su inicio y a su final (Shanley, 2007, p.18). Así, la autora concluye que los escritos sobre el contrato matrimonial de Locke fueron una pieza fundamental para los discursos de la política liberal: "John Locke solucionó los dos dilemas teóricos de los parlamentarios anteriores que habían intentado incorporar la visión del matrimonio como una relación jerárquica e irrevocable en un marco político liberal emergente" (Shanley, 2007, p.34).

Melissa Butler (2007) también argumenta que Locke fue el primer pensador a percibir que el "liberalismo" era contradictorio porque al mismo tiempo en que se basaba en la afirmación de la libertad natural a la humanidad, no aseguraba mucho más libertad a las mujeres que la permitida por el patriarcado ${ }^{11}$. Además, "Locke, en gran parte, aceptó el hecho empírico de la inferioridad de las mujeres y percibió que se fundamentaba en la naturaleza según lo ordenado por Dios" (Butler, 2007, p.105), esa afirmación de Locke consta del Primer Tratado, capítulo V, cuando dice que la Providencia no regaló ninguna autoridad de Adán hacía Eva, o de los hombres hacía sus esposas, pero que predijo/sugirió que las mujeres deberían someterse a sus maridos, pues esa es un fundamento de la Naturaleza (no de la Creación). Schochet (2007) argumenta que la utilización de la familia como base de la orden política ha sido utilizada desde Grecia, siendo esta un tipo de precursor estructural del orden político.

De una manera general, Locke con sus Tratados estableció una literatura de defensa de la naturaleza humana, pero también estableció una literatura que al no extender el poder igualitario a las mujeres, terminó por justificar y defender una orden social política

\footnotetext{
${ }^{10}$ El escándalo del Bill Clinton -1998 - que mantenía relaciones "inapropiadas" (palabras de Clinton) con una mujer en prácticas en el gobierno (Mónica Lewinsky) chocó a los EEUU no solamente por la moralidad, sino que por revelar que los hombres públicos son sexuados.

${ }^{11}$ Todavía, la autora afirma que "Locke no estaba interesado en crear un mundo en el cual todos los seres eran iguales; en su visión siempre iban a existir diferencias entre los individuos” (Butler, 2007, p.103).
} 
puramente masculina, que, aún hoy en día se hace visible pese a los avances del feminismo y de los diversos movimientos de mujeres buscando una mayor participación de la mujer en la arena política.

\section{El modelo Femocrata, el Feminismo de Estado y las estrategias femocraticas ${ }^{12}$}

La trayectoria de las mujeres en la vida política permite la posibilidad de diseñar acciones de resistencia contra relaciones de poder desiguales y excluyentes pautadas por el dominio masculino en la esfera pública y por el padrón de democracia "masculina". Estas acciones permiten analizar el desarrollo de nuevas formas de ejercer el poder político por parte de las mujeres, como la femocracia.

Rankin y Vickers (2001) argumentan que hacer política no es una acción restricta a los órganos gubernamentales, también, como lo señala un viejo eslogan feminista: "lo personal es político", es decir, se hace política de varias formas. Lo que existe es una división entre eses modos de hacer políticas y las llamadas "políticas oficiales" limitadas a los siguientes ámbitos: legislaturas, burocracias, cortes (leyes) y la policía. En las políticas oficiales las mujeres ejercen el poder político a través de sus cargos electivos, de la votación y del lobby, actúan en la política "no oficial" directa o indirectamente a través de su influencia en la opinión pública. Esto da lugar a la importancia del feminismo de Estado:

Una innovación importante en cómo las mujeres activistas pueden tener acceso a la toma de decisiones del gobierno fue el desarrollo de lo que se denomina "feminismo de Estado". El concepto se refiere a las "actividades de las estructuras del gobierno que trabajan formalmente con la promoción de la condición y de los derechos de las mujeres" (Stetson y Mazur 1995: 1-2). La evolución del feminismo estatal es importante para determinar si (...) el status de las mujeres que existe dentro de las estructuras del Estado ofrece oportunidades para que las mujeres logren el cambio o si existe principalmente para permitir que los gobiernos digan que están consultando a las mujeres y tomando en cuenta sus necesidades (Rankin y Vickers, 2001, p.6).

Así, las principales feministas responsables de teorizar el Estado fueron las del segmento radical en los Estados Unidos - con las lecciones aprendidas de la primera ola del feminismo, en los años 1960 en muchos países occidentales - fueron ellas también que empezaran a indagar el universo de las políticas públicas oficiales enfatizadas en el sistema patriarcal. De acuerdo con sus estudios, la red de instituciones del feminismo de Estado incluye agencias como ministerios específicos, secretarías, comisiones, etc. enfatizando temas que conciernen a la agenda feminista, dialogando abiertamente con los diversos movimientos de mujeres y las feministas, estableciendo así un puente entre el gobierno y la sociedad civil.

En la América Latina, a partir de los años 1970, se han fortalecido la institucionalización del feminismo en organismos públicos, y es reconocido como el feminismo institucio-

${ }^{12}$ Traducción libre: "El modelo femócrata de feminismo de Estado y estrategias femócratas". 
nal o "la institucionalización de intereses feministas" en el Estado (Stetson y Mazur, apud Ruiz, 2006, p. 147.) La contribución de la femocracia es un perfeccionamiento de la democracia con las críticas del rol del Estado en las políticas públicas a favor de la igualdad entre mujeres y hombres, independiente de cual sea la vertiente feminista. No existe, y tampoco podría existir, un consenso en el interior del movimiento feminista (sean liberales, radicales, post-estructuralistas, por ejemplo) a cerca del rol estatal en pro de los intereses de las mujeres, pero lo que hay en común es la defensa del paradigma de género en las políticas públicas promotoras de la igualdad y lucha contra la dominación patriarcal presente en las instituciones gubernamentales. Clarissa Paradis (2013) entiende el feminismo estatal como la cuarta ola del feminismo en América Latina, cuyos orígenes se encuentran en los estudios feministas sobre el Estado de Bienestar Social en los años 1980, teniendo como principal característica la organización de las demandas de los movimientos de mujeres en el interior de los mecanismos institucionales de los gobiernos. Al referirse al feminismo latinoamericano, Paradis (2013, p. 2) lo clasifica como "comunidades de políticas de género", y lo destaca de las acciones de los - "Mecanismos Institucionales de Mujeres" (MIM). Ruiz (2006, p. 167, 168), prefiere el término “democracia de género" para explicitar mejor la inclusión de hombres y mujeres en sus cambios efectivos de género.

Pese a que hay varias controversias a cerca del roles de la femocracia, es posible afirmar que la femocracia constituye en un ejercicio de comprensión del Estado como un aparato institucional organizado a partir de luchas políticas específicas de las mujeres. Esto consiste en afirmar que no existe la posibilidad de que el Estado se mantener neutro en relación al género, esto es, las organizaciones estatales son espacios de poder y de relaciones generificadas que pueden producir avances o retrocesos en términos de la igualdad o desigualdad del género. El feminismo institucional solamente puede ser reconocido como un feminismo del Estado desde el momento en que implemente acciones transversales a favor de la igualdad de género y estén constituidas dentro de una agenda feminista. Así, el nivel de influencia de las mujeres en las políticas puede ser evaluado de tres maneras: a) desarrollar un trabajo de presión independiente y autónomo a través de grupos de mujeres, particularmente organizaciones no-gubernamentales (ONG) y agencias de cooperación internacional, o movimientos sociales contra o/a favor del Estado, siendo reconocidas como feministas "institucionalizadas"13; b) actuar directamente en el aparato estatal para producir políticas públicas con enfoque del género e igualdad a fin de posibilitar el cambio del carácter patriarcal de las estructuras estatales; c) actuar en colectivos o instituciones feministas el carácter autónomo, siendo reconocidas como feministas "autónomas" (Paradis, 2013; Ruiz, 2006 \& Stromquist,1996).

Un caso peculiar se pasó en Nueva Zelanda y Australia con el surgimiento de las femócratas. Las femócratas (burócratas feministas) surgen de la "interacción de los movimientos de mujeres y los gobiernos administrados por asesoras feministas" (Rankin y Vickers, 2001,

\footnotetext{
${ }^{13}$ Para Costa (2005) "feminista institucionalizada es la forma peyorativa en que las auto-identificadas como feministas autónomas nombran aquellas ocupadas en las agencias bilaterales y multilaterales, en los organismos estatales y profesionales de ONGs feministas." http://www.revistagenero.uff.br/index.php/revistagenero/article/viewFile/380/285
} 
p. 6): "La experiencia Australiana con el feminismo de Estado ha alcanzado resultados significativo en las áreas estratégicas de antiviolencia, incluyendo (...) la integración efectiva de programas sensibles a las necesidades de las mujeres aborígenes". La estrategia femocrática es un modelo reconocido del feminismo de Estado, utilizado en Australia con buen suceso, capaz de transitar entre acciones e influencias públicas (de género) sobre la política (de género) institucionalizada, implicando así en políticas oficiales que atiendan a demandas feministas. El modelo de feminismo de Estado aplicado en Australia (la estrategia femócrata) ha logrado una mayor participación política de las mujeres en cuanto al voto obligatorio, siendo la participación de las mujeres hasta un 30\% en cámaras legislativa como el Senado, por ejemplo ${ }^{14}$; además han hecho viable una mayor capacidad de gastos para el desarrollo de las mujeres, y el cumplimiento de los tratados de cooperación internacionales. El buen resultado de ese modelo feminista viene del hecho de que sus representantes junto al gobierno dialogan constantemente con los diversos movimientos de mujeres y feministas, buscando conocer sus demandas y suplirlas, afirmando así sus condiciones de representantes de ese electorado femenino politizado. ${ }^{15}$ Sin embargo, las mujeres fueron solo receptoras de políticas públicas y solo recientemente también son partícipes en la formulación; los partidos políticos son predominantemente masculinos a pesar de la discusión de las cuotas de paridad. Eso generó que las mujeres buscaran otras opciones alternativas de llegada al poder y a la representación política, como la creación de los partidos feministas.

Así, el principal objetivo de la femocrácia es cambiar las relaciones políticas estatales para una efectiva igualdad de género, es decir, envolver todos los ministerios e instituciones a la problemática femenina y las políticas públicas equitativas hasta que toda la sociedad sea transformada en sus roles del género.

Entretanto, hay que apuntar algunas observaciones al modelo femocrata: A) A pesar de la presencia de las mujeres en las estructuras gubernamentales ser un dato importante que permite una ampliación de la democracia representativa femenina, es necesario considerar el hecho de que no todas las mujeres son feministas y eso puede conducir a ignorar la agenda feminista o al avance de pautas conservadoras; B) Considerar que algunos ministerios o programas liderados por las mujeres no sean tan influyentes al ponto de que no sea posible impulsar cambios significativos en las normas de género, a veces muchos tienen poca capacidad institucional para promover políticas públicas con enfoque de género; para medir el nivel de influencia es importante la observar el presupuesto financiero destinado a los ministerios y programas como una de las condiciones efectivas del empoderamiento político de las mujeres; C) Verificar la transversalidad de género en las políticas ministeriales y su interlocución con los municipios y con la sociedad civil.

Estas observaciones son muy importantes para el mejoramiento del ejercicio de la femocracia y para no ser confundida con la demagogia de los Estados que dicen ser pro-

\footnotetext{
${ }^{14}$ Las representantes de ese modelo femócrata junto al gobierno fueron reclutadas entre los movimientos de mujeres y feministas reconocidas, agregando legitimidad a esas voces.

${ }^{15}$ Ese escenario, por ejemplo, es diferente del feminismo de Estado de Canadá donde las representantes políticas y/o las representantes de agencias de mujeres/feministas son funcionarias de carrera y no, necesariamente, representan a las demandas feministas (Rankin y Vickers, 2001, p. 12).
} 
gresistas al incorporar la matriz de género pero no hay empeño en cambiar las normas sexistas presentes en la cultura política. A veces el Estado formula o apoya políticas públicas convencionales que refuerzan los roles de las madres y esposas, en vez de fortalecer o género oportunidades para su calificación y remuneración en el mercado de trabajo; así como también estimular el involucramiento de los padres en la educación de sus hijos o en las tareas domésticas ${ }^{16}$.

Lourdes Bandeira (s.f.), propone la separación entre las políticas públicas de género y las exclusivamente elaboradas para las mujeres, siempre y cuando estas últimas no de minimicen lo femenino haciendo énfasis en el rol de reproductora social de las mujeres, en la educación de los/as niños/as, entre otras preocupaciones sexistas, y no tanto por su empoderamiento y autonomía. Entonces, se considera que el ejercicio de la femocracia es muy necesario para el fortalecimiento de la democracia femenina ${ }^{17}$, por eso, vamos proceder en el próximo apartado a un recorrido por la femocracia en Brasil.

\subsection{Ejercicios de femocracia en Brasil - marcos democráticos}

¿Hay caminos que apuntan conquistas feministas en los espacios públicos y cotidianos de la vida política que pueden ser comparados al modelo político femocrata? En el transcurso de este apartado, queremos apuntar que es muy importante no considerar el éxito de un ejercicio femocrata solo por las conquistas electorales de las mujeres o mediante el aparato estatal, otros indicadores deben ser evaluados para que se pueda medir el alcance de este ejercicio, como por ejemplo, la participación femenina en ONGs, movimientos sociales, articulaciones con proyectos de naturaleza política que identifican temas de género o a cerca de los derechos de las mujeres, deliberación en conferencias, fórums y congresos.

En Brasil, la cultura política fue estructurada a partir de las nociones del orden público como masculina en oposición al mundo privado como femenino, relacionado a la familia y naturaleza femenina. Estas nociones ordenan el imaginario político de la dominación masculina y remiten, históricamente, a la cultura patriarcal que impone la separación entre mujeres y la vida pública. Lo cual consecuentemente, se traduce en una política con base en la autoridad y superioridad del hombre sobre la mujer, vista como sumisa e inferior en los cuadros del patriarcado. ${ }^{18}$ El gran marco de la lucha femenina en el campo po-

\footnotetext{
${ }^{16}$ Como señala Nelly Stromquist (1996), hay una nítida preferencia, por parte del Estado, en la proposición de políticas que discutan las desigualdades del acceso de las mujeres a educación pero no hay el mismo empeño en la identificación de las fuerzas sociales, económicas o ideológicas subyacentes a la subordinación y dominación femeninas.

17 "El Estado moldea las relaciones de género a través de las reglamentaciones relativas al divorcio, al matrimonio, al aborto, a la anticoncepción, a la discriminación salarial, a la sexualidad, a la prostitución, a la pornografía, a la violación y a la violencia hacia la mujer" (Walby apud Stromquist, 1996, p, 29).

${ }^{18}$ Eso no significa, sin embargo, que las mujeres estuvieran ausentes o pasivas en relación a la construcción política que marcó las fases más importantes de la historia política brasileña, sobretodo en el pasaje del Imperio a la República, marcada por fuertes rupturas institucionales. Barbara de Alencar, Maria Quitéria, Joana Angélica de Jesus, Jovita Feitosa son algunas de las mujeres combatientes por la Republica, sea en el campo de las ideas o en las batallas militares. Las primeras feministas del siglo XIX se encuentran en el movimiento de la defensa a la educación femenina y el derecho al voto, como Nisia Floresta, Josefina Alvares de Azevedo. (Prado \& Franco apud Pinsky \& Pedro, 2012, p.194).
} 
lítico se dio en dos fases distintas del republicanismo reciente: La primera, en el inicio del siglo XX, a través de la lucha por el derecho al voto y la participación electoral, cuyos nombres más significativos son Bertha Lutz, quien dirigió la campaña por el sufragio femenino a través de la organización de la asociación política Federación Brasileña para el Progreso de las Mujeres en la década de 1920, y Carlota P. de Queiroz, primera diputada federal en 1933. Varias estrategias fueran utilizadas por las mujeres para romper su exclusión en los espacios de poder, como los manifiestos escritos en periódicos de la época y la fundación de los partidos políticos, como el Partido Republicano Femenino (1910) por Leolinda Daltro y Gilka Machado, el cual defendió el sufragio, la emancipación y la independencia de las mujeres en el mundo del trabajo y la política. Daltro y Machado llegaran a organizar una marcha de mujeres en Río de Janeiro en 1917 a la que asistieron 90 mujeres. (Pinto, 2003, p.19) La segunda fase, al final de la Dictadura Cívico-Militar (1964-1984) corresponde al período de la democratización a finales de 1980, cuando las relaciones entre el Estado y la sociedad sufrieron cambios agudos cuyos efectos incidieran en el movimiento feminista. Los movimientos sociales se han organizado en torno a la lucha por la democracia, como "Mujeres Movimiento Directo Ya" con el llamado "feminismo de resistencia", y contó con su total apoyo. Inicialmente participaron las mujeres de clase media, pero no tenían un carácter eminentemente feminista porque no se discutía la condición opresiva de la mujer, como lo hacía el feminismo (Pinto, 2003, p.43).

Las cuestiones de género y de la "naturaleza femenina" se desarrolló a partir de los años 1980-1990 a través de los debates sobre los roles sociales y las tensiones entre lo público y lo privado, tan dispendiosos en términos de derechos igualitarios a la élite política patrimonial y patriarcal. En este contexto, se esboza un nuevo feminismo de bases institucionales, lo que profundiza su relación con el Estado en nombre de un proyecto de transformación social más amplia que incluía el establecimiento de la mujer como sujeto político y las reivindicaciones de una agenda de género. En la agenda, se discutió a cerca de las violencias contra las mujeres, las demandas de políticas públicas para la igualdad de género, el derecho a la guardería y los controvertidos derechos sexuales y reproductivos, entre otros. En este escenario, el feminismo asume la incorporación de las demandas de otros segmentos de mujeres como las negras, lesbianas, los movimientos populares de mujeres, con una gran participación de mujeres militantes de ONGs, grupos de reflexión, creación de departamentos de la mujer en los partidos políticos y la participación en conferencias nacionales e internacionales de la década de 1990, como la Cuarta Conferencia Mundial sobre la Mujer en Beijing. En el marco de esta Conferencia, se creó la Articulación de la Mujer Brasileña, la cual organizó a más de 800 grupos de mujeres en los 24 Estados de la Federación. (Pinto, p.101) Según Costa (2005, p. 9), esta conferencia "represento para el movimiento feminista brasileño una profundización de la articulación con el feminismo latinoamericano en términos de actuación conjunta gracias a una dinámica transnacional, a través de redes formales e informales", que fueran, sin duda, uno de los pasos más importantes para la femocracia aquí discutida.

Sin ninguna duda, este periodo fue marcado por el proceso de la institucionalización de las mujeres en el marco político de las luchas sociales al interior de las instituciones 
públicas a medida que han incorporado una nueva relación del feminismo con el Estado, la creación de las comisarías de policía de la mujer, los consejos de derechos, la ley de cuotas electorales, la elaboración de planos/programas o políticas nacionales y los mecanismos institucionales de mujeres.

Se aprobó la ley 9.100/95 de cuotas de paridad en 1995 a "posiciones en el legislativo y municipal que prevé el mínimo de 30\% y el máximo de $70 \%$ de candidaturas de cada sexo" (Sánchez, 2014, p.08). La ley fue ampliada en 1997 para los cargos legislativos federales, y en 2009 se hizo obligatorio; sin embargo, en 2010 hubo el incumplimiento de la ley por la mayoría de los partidos políticos, lo que lleva a los hombres a cubrir las vacantes restantes que serían preferentemente para las mujeres (Sánchez, 2014). La formulación de políticas públicas con perspectiva de género afecta la participación significativa de las mujeres en los organismos gubernamentales, como las comisarias policiales de mujeres (1985), los concejos municipales $(1983,1985)$, la creación de planes nacionales y el Programa de Atención Integral a Salud de la Mujer (PAISM) en 1983, y en la elección de la primera gobernadora (Iolanda Fleming en 1986) y senadora (Eunice Michiles en 1979, debido a la muerte del titular). Los slogans "Constituyente para valer lleva palabra de Mujer" y "Constituyente para valer hay que tener en cuenta a los derechos de la mujer" marcó el Comité político de Mujeres en el "lobby do batom"19 (1987-1999), y por el lema “ lo personal es político". Podemos decir que Brasil ha superado en parte la incorporación de las mujeres a cargos públicos a través de la muerte de sus titulares cuando sus suplentes (en este caso, algunas eran mujeres) asumen el poder, o por ser esposas de políticos, pero eso no significa que el camino está listo, todavía hay una larga senda para superar todas las estructuras patriarcales y sexistas que intentan hacer de las mujeres solo piezas meramente ilustrativas. ${ }^{20}$

Aunque no existe un consenso dentro del feminismo brasileño en cuanto a su participación en los consejos municipales y ministeriales, es posible observar los logros políticos de las mujeres en cargos de elección popular y formas alternativas de participación política. El miedo de perder la autonomía y debilitar la lucha contra las estructuras patriarcales del Estado ha traído varias rupturas importantes en el movimiento, tales como la división entre los grupos favorables a la participación y la deliberación de la mujer en los espacios públicos, y los grupos contrarios, conectados a los movimientos sociales de base y las organizaciones no gubernamentales que, no obstante, direccionan su diálogo de modo más eficaz junto al Estado. Esta es la gran paradoja del feminismo para tomar las pretensiones de un modelo femocrata. Por un lado, existe la necesidad de oponerse al Estado y ofrecer acciones de resistencia como un mecanismo de transformación y reinterpretación de las mujeres como "actrices" políticas, para usar la expresión de Elizabeth

\footnotetext{
${ }^{19}$ Lobby del pintalabios, comité creado por las senadoras y diputadas en ejercicio para militar en causas feministas y de género dentro del Congreso.

${ }^{20}$ Las Mujeres redijeron la "Carta de las Mujeres Brasileñas", primer documento de políticas públicas para las mujeres que evidenció la voz activa en la redacción de la Constitución de 1988.La presencia de mujeres militantes de los movimientos feministas durante la Constituyente reveló el poder político de las mujeres Fueron enviadas 04 ementas (propuestas) por entidades feministas con 243.068 firmas, y 03 de ellas trataban del trabajo doméstico para la jubilación de las amas-de-casa, el dossier Derechos de la Mujer con varios derechos sociales, y la legalización del aborto (Pinto, 77).
} 
Souza-Lobo (1991). Por otro, se entiende que es necesario actuar dentro del Estado para exigir acciones de promoción dela Igualdad de género dentro de los marcos feministas. Esto presupone la discusión de lo que se entiende por Igualdad y democracia dentro de una sociedad liberal como Brasil, o repensar la democracia a partir de las relaciones de género y no como un modelo dependiente del perfil político de un gobernante o de un Estado. Independiente de la elección, la femocracia se ejerce dentro y fuera del Estado pues el ejercicio de la política, en el sentido foucaultiano, es un ejercicio cotidiano, personal, que traviesa el individuo y el cuerpo social.

Entre los años 1990 y 2000, el movimiento feminista ya estaba más presente en los espacios institucionales y con una agenda de género más consolidada a partir de metodologías de participación y consultas populares, investigaciones académicas, reuniones y audiencias públicas, organizaciones de mujeres y colectivos feminista en conferencias nacionales, municipales y estatales generando así un diálogo más estrecho entre la sociedad civil y las instancias gubernamentales, tales como la "Asamblea Femenina” (1999-2011). En las palabras de Paradis (23), hay en Brasil una especie de "feminismo estatal de carácter participativo" con una red de instituciones del feminismo de Estado (agencias, ministerios de mujeres, secretarías, comisiones, etc.).

En los dos mandatos del presidente Luis Inácio Lula da Silva (2003 a 2011), se elaboraron nuevas políticas de género como la promulgación de la ley 11.340 de 7/8/2006, la Ley Maria da Penha, la implementación del Plan Nacional de Políticas para las Mujeres (resultado de las tres conferencias nacionales realizadas en 2004, 2007 y 2011), la Política Nacional de Seguridad Alimentaria y Nutricional en el Programa Hambre Cero, la Política de Promoción de la Igualdad Racial, coordinada por la Secretaría Especial de Políticas de Promoción de la Igualdad Racial -SEPPIR; y la Política de la Promoción de la Igualdad de Género, impulsada por la Secretaría de Políticas para las Mujeres ${ }^{21}$, creada en 2003, con presupuesto proprio y vinculada directamente a la Presidencia de la República. Entre las acciones más significativas de este feminismo institucional están las siguientes: - el refuerzo de la Bancada Femenina del Congreso Nacional; - La creación en 2009 de la Fiscalía de la Mujer en la Cámara de los Representantes/Diputados; - El documento "Articulando la Lucha Feminista en las Políticas Públicas" promovidas por AMB-Articulación de Mujeres Brasileñas; y el lanzamiento de la Plataforma Política Feminista por el Movimiento Nacional de Mujeres ${ }^{22}$ en 2002.

Se verificas, entonces, en este breve recorrido histórico la evolución del feminismo estatal en las instancias gubernamentales y en las entidades de la sociedad civil, lo que permiten evaluar el estatus de las mujeres a partir de las estructuras del Estado y, sobretodo, su fuerza política presente en las diversas fases de su empoderamiento y capacidad de intervención política.

\footnotetext{
${ }^{21}$ Lula ha sido bastante criticado por no indicar una feminista para asumir tal Secretaria.

${ }^{22} \mathrm{http}$ ///www.institutobuzios.org.br/documentos/PLATAFORMA\%20POLITICA\%20FEMINISTA.pdf
} 
3.2 Reflexiones finales: Dilma Vana Rousseff: Primer Mandato (2011-2014) - la estética del juego político en el marco de la femocracia Brasileña

Para entender la dimensión estética de la política es necesario destacar qué elementos conceptuales se usaran en este apartado. Para el filósofo Jacques Rancière (2005) existe en la base de la política una estética entendida a través del principio Kantiano que es como un sistema de formas determinadas a priori lo que se da por sentir. Así, sigue el filósofo, esa estética es "un recorte de los tiempos y de los espacios, del visible y de lo invisible, de la palabra y del ruido que definen al mismo tiempo el lugar y lo que está en juego en la política como una forma de experiencia" (Rancière, 2005, p. 17).

De esta forma, y según la comprensión de Rancière (2005), la política es el terreno donde se ocupa de todo lo que se ve y todo aquello que se puede decir sobre lo que se ha visto, de los que tienen la competencia para ver y la calidad para decir, o sea, es un juego estético donde los propietarios del poder de ver y decir son aquellos que juegan las cartas y dan las bases del comportamiento en ese juego (en su caso, ese juego estético de la política).

En Brasil, vemos muy claro esa estética política a través del entrelazamiento entre la letra (el discurso político) y la imagen política. Dilma Rousseff es la primera presidenta de Brasil, y sin embargo los medios audiovisuales (de una forma general) diseñaran una presidenta con caracteres marcadamente masculinos, como mucha autoridad, enfatizaran el hecho de que Rousseff no tiene un matrimonio actual, e incluso cuestionan la sexualidad de la presidenta. Sin embargo, el tema de la sexualidad de la presidenta es frecuentemente explotado por los medios de comunicación (televisada, escrita y redes sociales) con un lenguaje sexista (la histeria de la presidenta ${ }^{23}$ ) o con imágenes que sugestionan el acto sexual ${ }^{24}$, por lo que, esos son elementos estéticos de un discurso patriarcal que aleja del poder público a las mujeres. En ese sentido, hay que destacar un pasaje de su discurso de posesión como jefa de Estado en 2011: "Vengo para abrir las puertas para que muchas otras mujeres puedan también, en el futuro, ser presidentas; y para que -en el día de hoytodas las mujeres brasileñas sientan el orgullo y la alegría de ser mujer ${ }^{25}$.

De ese modo, podemos afirmar que el primer mandato de la presidenta Dilma Rousseff llevó elementos estéticos de una femocracia cuando, por ejemplo, construyó su cuerpo ministerial con la mayoría de mujeres ministras (12 en total $)^{26}$, mucho más que los gobier-

\footnotetext{
${ }^{23}$ Para saber más, ver: “Los siete crímenes de Dilma - Revista Isto É”: http://www.istoe.com.br/reportagens/449533. OS+7+CRIMES+DE+

${ }^{24}$ Ver nota de repudio de los movimientos de mujeres Brasileñas: http://www.mulheresseguras.org.br/nota-de-repudio-movimento-de-mulheres-repudia-adesivos-com-mensagem-sexista-e-uso-da-imagem-da-presidenta/

${ }^{25}$ Ver el discurso de la Presidenta Dilma Rousseff en: http://www2.planalto.gov.br/acompanhe-o-planalto/discursos/discursos-da-presidenta/discurso-da-presidenta-da-republica-dilma-rousseff-durante-compromisso-constitucional-perante-o-congresso-nacional

${ }^{26}$ A saber: Gleisi Hoffmann (Ministra Jefe de la Casa Civil); Miriam Belchior (Ministra del Planeamiento); Graça Foster (Presidenta de la Petrobras); Ideli Salvatti (Ministra de las Relaciones Institucionales); Helena Chagas (Ministra de la Secretaría de la Comunicación Social); Tereza Campello (Ministra del Desarrollo Social); Izabella Teixeira (Ministerio del Medio Ambiente); Luiza Bairros (Ministra del Estado -jefa de la SEPPIR- Secretaria de Políticas de Promoción de la Igualdad Racial); Marta Suplicy (Ministra de la Cultura); Eleonora Menicucci (Ministra de la Secretaría de Políticas para las Mujeres); Maria do Rosário (Ministra de la Secretaría de los Derechos Humanos) y Rosa Weber (Ministra del Supremo Tribunal Federal).
} 
nos antecesores a ella. Es cierto que no basta solamente la incorporación de las mujeres en programas o ministerios, pero el gobierno Dilma ha hecho esfuerzos para fortalecer la transversalización de las políticas para las mujeres en al ámbito de todos los ministerios, a cargo del Comité de Monitoria del Plan Nacional de Políticas para las Mujeres y en las Agendas Transversales ${ }^{27}$ del Plan Plurianual (2013-2015). Eso se confirma por la creciente participación de las mujeres en los consejos de políticas públicas en los ámbitos estatal y municipal (hay 24 Consejos Estatales, 15 Comités de Género y 420 Consejos Municipales de Derechos de la Mujer) ${ }^{28}$.

La política externa también fue impactada por elementos femocraticos cuando el gobierno Dilma Rousseff (primero mandato) públicamente condenó el apedreamiento de la Iraniana Sakineh Ashtiani, lo que significó una ruptura con el gobierno anterior que se esquivaba de esos temas diplomáticos y asumía una posición más moderada. En un análisis sobre sus discursos durante el primer mandato, la investigadora Danielle Costa da Silva (2015) relata que la palabra "mujeres" fue la décima primera palabra más proferida por la presidenta en sus discursos públicos oficiales. En lo tocante a la política interna, las políticas acuñadas por la presidenta Rousseff en su primer mandato buscaban la protección y el empoderamiento de las mujeres brasileñas, siendo estas figuras centrales en los programas de distribución de renta y en el combate a la desigualdad social (Costa da Silva, 2015). Además, el combate a la violencia hacía la mujer se hizo con programas como: "Mujer: vivir sin violencia" ${ }^{29}$, la creación de comisarías especializadas sobre la mujer, la vigilancia y fiscalía sobre la "Lei Maria da Penha" (de combate a la violencia hacia las mujeres), el programa de combate al índice de mortalidad materna y políticas de salud pública, bien como la elaboración de planos de acción de políticas favorables al desarrollo femenino en la sociedad, como el "Plan Nacional de Políticas para las Mujeres" (2013-2015) ${ }^{30}$. Las mujeres fueron receptoras de políticas públicas que han impulsado el ejercicio femocrata a partir de los siguientes ejemplos: - se han ampliado la red de servicios públicos de atendimiento a las mujeres como las Unidades Móviles de Atendimiento a las Mujeres Rurales en Situación de Violencia;- el fortalecimiento del Parlamento con la Bancada Femenina; - la implementación del Programa Pro-Equidad de Género y Raza en las empresas públicas y privadas con el objetivo de desarrollar una nueva cultura organizacional basada en la igualdad de género; - la creación del Comité de Género en cada órgano ministerial (en 2014, eran 15 comités) 31; - aprobación de la Ley del Feminicídio, (Ley no 13.104, de 09 de marzo de 2015).Todavía, temas sensibles a la agenda feminista, como el aborto, no fueron

El segundo mandato del gobierno Lula (2007-2010), por ejemplo, tuvo solo 5 mujeres como ministras, y el gobierno FHC (Fernando Henrique Cardoso - de 1999-2002) tuvo 3 ministras en su segundo mandato.

${ }^{27}$ Agenda Transversal reúne el conjunto de compromisos del gobierno para garantizar derechos públicos a los diversos grupos sociales vulnerables y hacer un balance de las políticas del gobierno federal para Mujeres, Juventud, Igualdad Racial, Poblaciones LGBT y de la Calle, Niño y Adolescente, Mayores, Deficientes y Pueblos Indígenas.(Texto Base - $4^{\underline{a}}$ Conferencia Nacional de Políticas para las Mujeres In: http://www.spm.gov.br/4cnpm/assuntos/Documentos)

${ }^{28}$ Ver más en: https://www12.senado.gov.br/institucional/procuradoria_

${ }^{29}$ El Programa proporciona la implantación de la Casa de la Mujer Brasileña en todas las capitales del país y la ampliación de la Central de Atendimiento a la Mujer - Disque 180.

${ }^{30}$ Puede ser descargadogratuitamenteaquí: http://www.compromissoeatitude.org.br/wp-content/uploads/2012/08/ SPM_PNPM_2013.pdf

${ }^{31}$ Ver más: http://www.spm.gov.br/4cnpm/assuntos/Documentos 
abordados por la presidenta por motivos políticos, aunque la misma se posicionó favorable a una revisión de la ley del aborto brasileña que es bastante limitadora.

De una forma general, la femocracia brasileña camina a pasos lentos, con una oratoria bastante satisfactoria pero una praxis con fallos, también es importante resaltar que fue la primera vez que una mujer presidió Brasil y que esa deuda histórica con el desarrollo femenino en el espacio público va llevar aún algunas décadas para ser saldada. Como parte de la estética de un gobierno democrático puede resaltar: el compromiso ${ }^{32}$ con la ampliación de la posición de las mujeres en la toma de decisiones, en puestos de dirección, la construcción de organismos ejecutivos de políticas para las mujeres, en el parlamento la necesidad de ampliación de las llamadas cuotas femeninas en la política - para los partidos políticos en Brasil son de un mínimo del 30\%, siendo que las mujeres ya son mayoría de la población brasileña). El seguimiento de las estéticas femocraticas en una democracia urge, puesto que como bien dijo la diputada brasileña Luiza Erundina en medio a la actual crisis política de Brasil: "Quien sabe de las necesidades y de los intereses de las mujeres somos las mujeres. No aceptamos que ningún hombre nos sustituya para decirnos cuales son nuestros derechos." Y la diputada, que en un determinado momento de una votación importante para las mujeres dentro de la Cámara de Diputados brasileña sobre una tentativa de frenar la escalada de derechos de las mujeres sin haber consultado las diputadas mujeres, interrumpió la sección, tomó la palabra y dijo: "Nosotras somos más de $50 \%$ de la población brasileña y somos menos de 10\% en esa casa. Esa desventaja en la representación [paritaria] es un déficit en la democracia brasileña."33

Al entender la femocracía como un ejercicio de comprensión del Estado organizado a partir de luchas políticas específicas de las mujeres, de su participación política y, sobretodo, a la toma de decisiones gubernamentales con vistas a la promoción de los derechos de las mujeres, entonces, el gobierno Dilma ha dado pasos importantes para una estética femocrata.

De todos modos, este artículo buscó evidenciar los aspectos estructurantes de un modelo femocrático aplicado en un gobierno Suramericano resaltando la necesidad de implementar más herramientas estéticas femocráticas en la democracia actual.

\section{Referencias}

Alvarez, Sonia (2001). Los feminismos latino-americanos se globalizan: tendencias de los años 90 y retos para un nuevo milenio. In: Dagnino, Evelina \& Escobar, Arturo (Org). La política de las culturas y las culturas de la política: revisando los movimientos sociales latinoamericanos. Bogotá: Taurus. Aristóteles (2004). Política. Nova Cultural. São Paulo.

\footnotetext{
${ }^{32}$ Para saber más: texto original detallado del compromiso: http://www.compromissoeatitude.org.br/wp-content/ uploads/2012/08/SPM_PNPM_2013.pdf

${ }^{33}$ Para saber más: http://agenciabrasil.ebc.com.br/politica/noticia/2016-04/em-meio-polemicas-camara-aprova-criacao-das-comissoes-da-mulher-e-do-idoso
} 
BANDEIRA, Lourdes (s.f). Fortalecimento da Secretaria Especial de Políticas para as Mulheres - avançar na transversalidade da perspectiva de Gênero nas Políticas Públicas. Convênio Comissão Econômica para América Latina e Caribe - CEPAL. Secretaria Especial de Política para as Mulheres - SPM.

Bobbio, Norberto (2000). O futuro da democracia. 9a ed. Trad. Marco Aurélio Nogueira. Ed: Paz e Terra. São Paulo.

Butler, Melissa A. (2007). Early liberal roots of Feminism: John Locke's attack on patriarchy. In: Hirschmann, Nancy J. \& McClure, Kirstie M. (eds.) (2007), Feminist Interpretations of John Locke, Pennsylvania State University Press.

CARVER, TERRELL (2007). Gender and narrative in Locke's Two Treatises of Government. In: Hirschmann, Nancy J. \& McClure, Kirstie M. (eds.) (2007), Feminist Interpretations of John Locke, Pennsylvania State University Press.

Costa, Ana Alice A. (2005). Movimento feminista no Brasil: Dinâmicas de uma intervenção política. Recuperado de: http://www.revistagenero.uff.br/index.php/revistagenero/article/viewFile/380/285.

Costa da Silva, Danielle (julho de 2015). Política externa Brasileira de direitos humanos do governo Dilma Rousseff (2011-2014): análise de conteúdo de discursos oficiais. 5ำ Encontro Nacional da ABRI. Minas Gerais. Brasil.

Davis, Natalie Zemon (1991). A mulher na política. In: Duby, Georges \& Perrot, Michelle. História das mulheres no Ocidente: Do Renascimento à Idade Moderna.Porto: Ed.Afrontamento.

FARAh, Marta Ferreira SAntos (2004). Gênero e políticas públicas. Revista Estudos Feministas, Florianópolis, 12 (1): 47-71.

FILMER, Sir Robert (1680). Patriarcha. Recuperado de: http://www.constitution.org/ eng/patriarcha.htm

Foucault, Michel. (1995). O sujeito e o poder. En: Rabinow, P. \& Dreyfus, H. Michel Foucault. Uma trajetória filosófica. Forense Universitária. Rio de Janeiro.

Hirschmann, Nancy J. \& McClure, Kirstie M. (eds.) (2007), Feminist Interpretations of John Locke, Pennsylvania State University Press.

Locke, John (2003). O segundo tratado sobre o governo. Nova Cultural. São Paulo.

OliveIRA, Richard Romero (2014). Platão e a questão da democracia na República. Revista Estudos Filosóficos, no 12. DFMI-UFSJ. São João del Rei - MG. Recuperado de: http:// www.ufsj.edu.br/portal2-repositorio/File/revistaestudosfilosoficos/art3\%20rev12. pdf

PARADIS, Clarisse (2013). O papel e o desenvolvimento dos mecanismos institucionais de mulheres na América Latina: uma quarta onda do feminismo em curso na região?. Seminário Internacional Fazendo Gênero 10 (Anais Eletrônicos), Florianópolis. http://www.fazendogenero.ufsc.br/10/resources/anais/20/1384203109_ARQUIVO_ClarisseParadis.pdf

Pateman, C. (1992). Participação e Teoria Democrática. Ed. Paz e Terra. Rio de Janeiro.

Pinto, Celi R.J. (2003). Uma história do feminismo no Brasil. São Paulo: Fundação Perseu Abramo. 
Fernanda Pattaro / Ana Cláudia Delfini La estética del juego político en el marco de la Femocracia Sur Americana

Platão (2004). A República. Nova Cultural. São Paulo.

Prado, Maria ligia \& Franco, Stella Scatena (2012). Participação feminina no debate público Brasileiro.In: Pinsky, Carla B. \& Pedro, Joana M. Nova História das Mulheres. SP: Contexto.

RANCIÈRE, JACQUES (2005). A partilha do sensível: estética e política (trad. Monica Costa Netto). São Paulo: Exo.

Rankin, L. Pauline; Vickers, Jill \& Field, Anne-Marie (2001). Women's movements and State Feminism: integrating diversity into public policy. Recuperado de: http://www. bcsth.ca/sites/default/files/Rankin\%20and\%20Vickers-\%20Integrating\%20Diversity\%20into\%20Public\%20Policy.pdf

Rodrigues, HelenA. A. (2004). In Defense of Women: Equality in Locke's Political Theory Paper presented at the annual meeting of the The Midwest Political Science Association, Palmer House Hilton, Chicago, Illinois. from http://www.allacademic.com/ meta/p82934_index.html

Ruiz, Yolanda Jubeto (2006). Los presupuestos publicos con enfoque de género: instrumento de análisis de la política económica desde la perspectiva feminista. Tesis Doctoral. Universidad Pública del País Basco. Facultad de Ciencias Económicas y Empresariales. Bilbao.

SARTI, Sintia (set. 1998). 0 início do feminismo sob a ditadura no Brasil: o que ficou escondido. In: Congresso internacional da Lasa, 21, 1998, Chicago. Anais... Chicago: Illinois.

SHANLEY, MARY LYNDOL (2007). Marriage and social contract in seventeenth-century English political thought. In: Hirschmann, Nancy J. \& McClure, Kirstie M. (eds.) (2007), Feminist Interpretations of John Locke, Pennsylvania State University Press.

Stetson, Dorothy McBridge \& Mazur, Amy (eds) (1995): Comparative State Feminism. Sage Publications.

Stromquist, Nelly P. (1996) Políticas públicas de Estado e eqüidade de gênero: Perspectivas comparativas. Revista Brasileira de Educação. Jan/Fev/Mar/Abr. 1.

ScHOSHET, GoRdon (2007). Models of politics and the place of women in Locke's political thought. In: Hirschmann, Nancy J. \& McClure, Kirstie M. (eds.) (2007), Feminist Interpretations of John Locke, Pennsylvania State University Press.

SommerviLE, J.P. (s.f). Theories of property, liberalism, gender and John Locke. Recuperado de: http://faculty.history.wisc.edu/sommerville/283/283\%20session09.htm

Souza-Lobo, Elisabeth (1991). A classe operária tem dois sexos: trabalho, dominação e resistência. São Paulo: Brasiliense.

\section{Websites consultados}

Articulação de Mulheres Brasileiras (2009): Articulando as lutas feministas nas políticas públicas. http://articulacaodemulheres.org.br/wp-content/uploads/2015/06/ Texto-base-8-AMB-Articulando-a-Luta-2009-Democratiza\%C3\%A7\%C3\%A3o-dagest $\%$ C3\%A3o.pdf 
Carta das Mulheres aos Constituintes (1987): http://www2.camara.leg.br/atividade-legislativa/legislacao/Constituicoes_Brasileiras/constituicao-cidada/constituintes/aconstituinte-e-as-mulheres/Constituinte\%201987-1988-Carta\%20das\%20Mulheres\%20aos\%20Constituintes.pdf

Palavra de Mulher: oito décadas do direito de voto (2012): http://bd.camara.gov.br/bd/ bitstream/handle/bdcamara/7367/palavra_mulher_2ed.pdf?sequence=3 